\title{
The Scalenus Accessorious Muscle
}

\author{
El Músculo Escaleno Accesorio
}

Rajanigandha V.; Anu V. Ranade; Mangala, M. Pai; Rajalakshmi Rai; Latha V. Prabhu \& Soubhagya R. Nayak

\begin{abstract}
RAJAnigandha, V.; RANADE, A. V.; PAI, M. M.; RAI, R.; PRABHU, L. V. \& NAYAK, S. R. The scalenus accessorius muscle. Int. J. Morphol., 26(2):385-388, 2008.

SUMMARY: Many of the anatomical variations that are inadequately described or quantified are actually more clinically and surgically significant than being just anatomical curiosities. We report about such a variation where an aberrant slip existed in the scalene group, in a 56 year old embalmed female cadaver. This kind of variation may affect the size of the scalene triangle, and thus, may potentially result in varied signs and symptoms in patients vulnerable to thoracic outlet syndrome (TOS). Proximity of the scalene muscles to the brachial plexus, subclavian artery and vein, coexisting with aberrant slips or bundles may also predispose to compression syndromes.
\end{abstract}

KEY WORDS: Scalene muscles; Aberrant slip; Thoracic outlet syndrome; Subclavian artery; Brachial plexus.

\section{INTRODUCTION}

The scalene muscles are paravertebral muscles which begin at the first and second ribs and pass up into the sides of the neck, varying in the number of their costal and vertebral attachments, as well as in the interrelationships caused by the fusion of numerous fasciculi. Frequently, due to faulty cleavages derived from a common muscle mass it is not uncommon to see the presence of accessory slips or fibrous bands. Of the three scalene muscles, anterior, middle and posterior, it is the scalenus anterior (anticus), which is clinically more important. Anterior scalene muscle arises from the anterior tubercles of the transverse processes of third or fourth to the sixth cervical vertebrae (Hollinshead, 1968). Its location is identified by the lateroposterior edge of the sternocleidomastoid muscle. It passes anterolaterally to be inserted by narrow tendon on the upper surface of the first rib between the groove for the subclavian artery and that of the vein. The middle scalene muscle (scalenus medius), typically the largest of the scalene group, arises from the transverse processes of most of the cervical vertebrae and inserts into the first rib behind or posterolateral to, the groove for the subclavian artery. Scalenus posterior muscle is a short muscle with no important relations except forming the floor of posterior triangle. It has been regarded as the posterior part of the scalenus medius muscle and often it is difficult to separate these two muscles from each other. Between the scalene muscles, the nerve roots of brachial plexus unite to form three trunks, which emerge from the interscalene groove to lie cephaloposterior to the subclavian artery, as it courses along the upper surface of the first rib. This neurovascular bundle forms the important posterior relation of the anterior scalene muscle. Because of its intimate relation to the brachial plexus the anterior scalene muscle has been thought to be responsible for certain clinical manifestations of pressure upon the plexus, as spasm of this muscle has been thought to exert pressure upon the plexus either directly or indirectly (Hollinshead).

\section{CASE REPORT}

During routine educational dissection for the undergraduates, we came across a variation in the scalene muscle, in a 56 year old embalmed female cadaver. The lateral aspect of the left side of neck was dissected, with the fascia and fatty tissue being removed. The middle thirds of the clavicle was excised to get a clear view of the anomaly. The sternocleidomastoid muscle was retracted, thereby exposing the anomaly along with the subclavian vessels and the brachial plexus. An accessory muscular fasciculus measuring $6.2 \mathrm{~cm}$ in length and $1.3 \mathrm{~cm}$ in width was seen to be arising from the middle of the anterior surface of scalenus medius muscle. As the presence of such a muscular aberration has not been reported earlier in the literature we 
have named it as scalenus accessories muscle. It descended downwards and laterally to merge with the tendon of scalenus anterior muscle towards its insertion. The upper trunk of brachial plexus was present between scalenus anterior muscle and the variant muscle in the upper portion. The subclavian artery and the middle and lower trunks of brachial plexus were found to traverse beneath this variant slip, thereby decreasing the space between scalenus anterior and scalenus medius muscles for their exit and thereby predisposing to neurovascular compression. The position of subclavian vein was normal but however it was seen to be looped by an accessory phrenic nerve which arose as a twig from the nerve to subclavius. Furthermore, the subclavian artery and trunks of brachial plexus were crossed by numerous veins anteriorly, which drained into the subclavian vein of same side. No marked anomalies in the formation and branching pattern of brachial plexus and subclavian vessels were found.

\section{DISCUSSION}

The causes of pressure on the neuro-vascular bundle of the upper limb are many and varied. No one cause such as clavicular pressure, aneurysm, or abnormal costal element can explain all cases, as there were patients whose symptoms were typical of compression but showed no acquired or birth related reasons. Radiologists reported frequent examples of cervical rib without ill consequences. TOS is one such general term used for problems stemming from nerve or blood vessel compression in their passage from the cervical area toward the axilla and proximal arm either at the interscalene triangle, the costoclavicular triangle, or the subcoracoid space. Presence of cervical ribs, anomalous muscles, and fibrous bands may further constrict these areas (Koknel Talu, 2005).

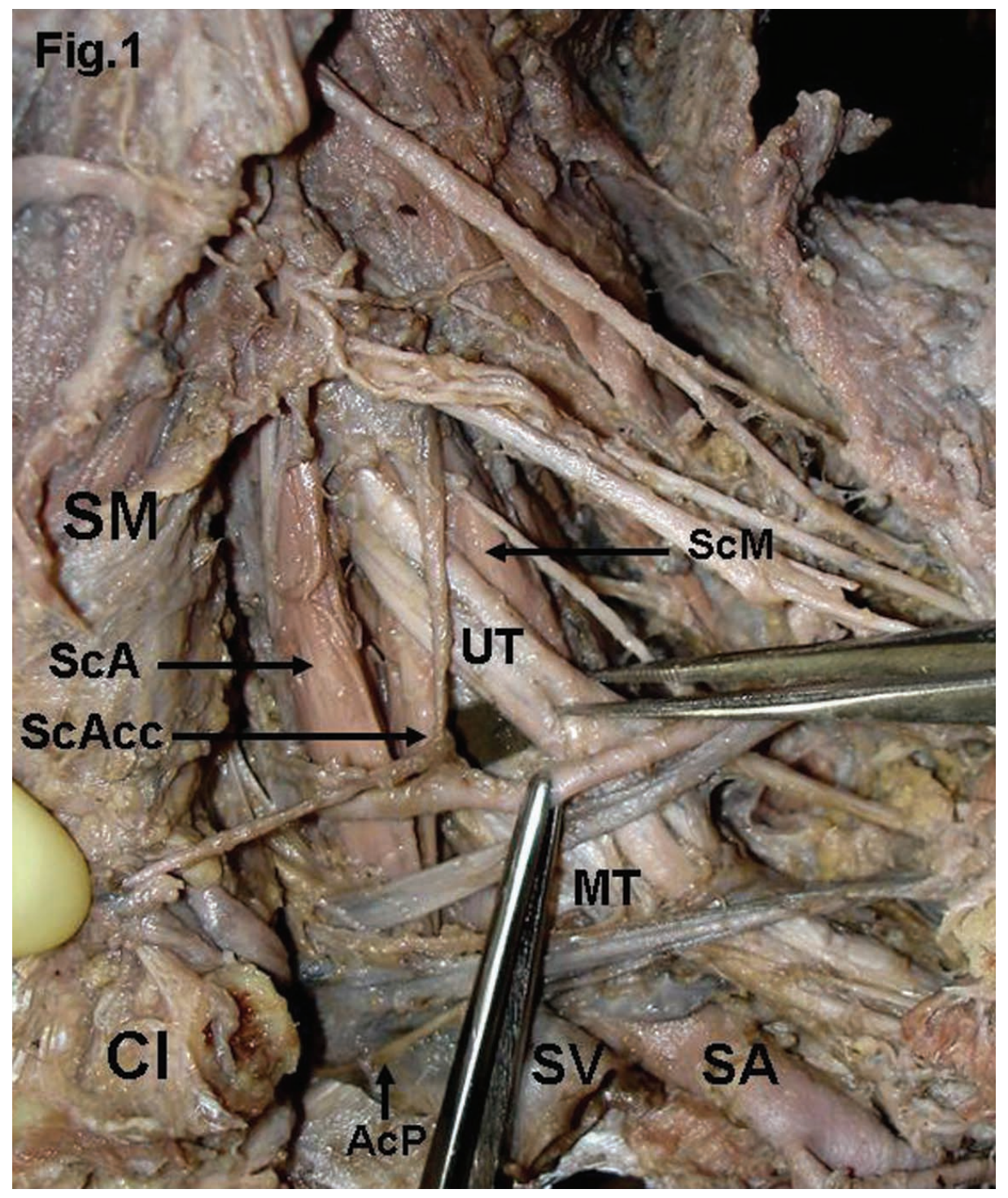

Fig. 1. The lateral aspect of the left side of neck is seen. The middle thirds of the clavicle $(\mathrm{Cl})$ is excised to get a clear view. Sternocleidomastoid muscle $(\mathrm{SM})$ is retracted. The upper trunk of brachial plexus (UT) can be seen traversing between the scalenus anterior muscle ( $\mathrm{ScA})$ and the scalenus accessorius muscle ( $\mathrm{ScAcc})$. The scalenus medius muscle (ScM), the middle trunk of brachial plexus (MT), the subclavian artery (SA) and vein (SV) and the accessory phrenic nerve (AcP) can also be appreciated. 
There have been reports of anomalous muscular slips between scalenus anterior and scalenus medius muscles. These anomalous muscular slips sometimes arose from scalenus medius muscle and ran into scalenus anterior muscle or vice-versa (Yamamoto, 1992). Since these muscles are derived from a common muscle mass, any faulty cleavage results in an anomaly (Hollinshead). The variant muscle slip observed in the present case may be a well developed remnant of such a faulty process. Harry et al. (1997) reported the commonly described anatomical relationship of the brachial plexus as lying between the scalenus anterior and scalenus medius muscles, in $60 \%$ of instances. The most common variation was the penetration of the AS by the $\mathrm{C} 5$ and/or C6 ventral rami. In $15 \%$ of cases, C5 and C6 roots may fuse before piercing the anterior scalene muscle or $\mathrm{C} 5$ root alone can pierce the belly of anterior scalene muscle, as seen in $13 \%$ of cases. In our case, the upper trunk of brachial plexus was present between scalenus anterior muscle and the variant muscle in the upper portion, where as the middle and the lower trunk of brachial plexus along with the subclavian artery emerged beneath the variant slip and scalenus medius muscle in the lower part of neck. Similarly, Hare \& Rogers (1981), reported a case of compression of the lowest trunk of the brachial plexus by a fibrous scalenus medius muscle band that connected the transverse process of the seventh cervical vertebra, to the first rib. Such cases are very rare but are well defined cause of arm pain.

There also have been few case reports of absence of scalenus anterior muscle. In one such case reported by Murakami et al. (2003) the absent muscle was substituted by aberrant muscle slips that arose from lower vertebrae and descended in front of the ventral rami of the lower cervical nerves (Murakami). These aberrant slips then ran between the ventral rami of the eighth cervical and first thoracic nerves, and were fused with the right scalenus medius muscle. Necdet et al. (2007), case report, highlights about a subclavian artery piercing scalenus anterior muscle while the roots $\mathrm{C} 8$ - T1 of brachial plexus passed behind scalenus medius muscle with the exception of normal course.

While the diagnosis of a pressure lesion at the cervicobrachial junction is usually simple, the causes of such pressure are so varied and obscure that without a thorough knowledge of the relevant anatomy it is not possible to forecast the exact cause in all cases. Having decided on clinical grounds, radiographic evidence, and the failure of conservative treatment, that operation is indicated, the approach should be frankly exploratory through an adequate incision that is wide enough to allow thorough investigation of the cause of pressure (Telford \& Mottersead, 1948). Anatomic analyses during operations for TOS, along with cadaver dissections, have disclosed several types of fibromuscular bands in addition to bony deformities predisposing for neurovascular compression (Roos, 1976). Therefore knowledge of these possible variations is very important to surgeons in performing anesthetic blockade to the brachial plexus or in surgical procedures, such as decompression or scalenotomy; otherwise it is to invite failure.

RAJANIGANDHA, V.; RANADE, A. V.; PAI, M. M.; RAI, R.; PRABHU, L. V. \& NAYAK, S. R. El músculo esaleno accesorio. Int. J. Morphol., 26(2):385-388, 2008.

RESUMEN: Muchas de las variaciones anatómicas no están suficientemente descritas o cuantificadas y son actualmente clínica y quirúrgicamente significativas más que curiosidades anatómicas. Reportamos una variación anatómica en el grupo de los músculos escalenos, presente en un cadáver de una mujer de 56 años. Este tipo de variación puede afectar el tamaño del triángulo escalénico y por lo tanto, puede potencialmente resultar en variados signos y síntomas en pacientes vulnerables al síndrome de salida torácica. La proximidad de los músculos escalenos con el plexo braquial, arteria y vena suclavias, coexistiendo con fascículos aberrantes pueden predisponer a síndromes de compresión.

PALABRAS CLAVE: Músculos escalenos; Fascículo aberrante; Síndrome de salida torácica; Arteria subclavia; Plexo braquial.

\section{REFERENCES}

Hare, W. S. \& Rogers, W. J. The Scalenus medius band and the seventh cervical transverse process. Diagn Imaging., 50(5):263-8, 1981.

Harry, W. G.; Bennett, J. D. \& Guha, S. C. Scalene muscles and the brachial plexus: anatomical variations and their clinical significance. Clin Anat., 10:250-2, 1997.

Hollinshead. W. H. Anatomy for surgeons: The head and neck, $3^{\text {rd }}$ Ed. New York. Harper and Row publishers, 1968. pp. 507-10.

Koknel Talu, G. Thoracic outlet syndrome. Agri., 17(2):5-9, 2005.

Murakami, S.; Horiuchi, K.; Yamamoto, C.; Ohtsuka, A. \& Murakami T. Absenceof scalenus anterior muscle. Acta Med Okayama., 57(3):159-61, 2003.

Necdet, K.; Bulent, Y.; Cenk, K. \& Hasan O. Multiple anomalies of brachial plexus: a case report. Neuroanatomy, 6: 21-3, 2007. 
RAJANigandha, V.; RANADE, A. V.; PAI, M. M.; RAI, R.; PRABHU, L. V. \& NAYAK, S. R. The scalenus accessorius muscle. Int. J. Morphol., 26(2):385-388, 2008.

Roos, D. B. Congenital anomalies associated with thoracic outlet syndrome: Anatomy, symptoms, diagnosis and treatment. Am. J. Surg., 132(6): 771-8, 1976.

Telford, E. D. \& Mottersead, S. Pressure at the cervicobrachial junction: An Operative and Anatomical Study. Manchester, England, 30B (2):249, 1948.

Yamamoto, C. Typological interrelationships of the human scalenus muscles, brachial plexus and subclavian artery. Okayama Igakkai Zasshi (JOMA)., 104: 205-9, 1992.
Correspondence to:

Dr. Rajanigandha V.

Department of Anatomy,

Center for Basic Sciences,

Kasturba Medical College,

Bejai, Mangalore- 575004 ,

Karnataka - INDIA

Tel : +918242211746

Fax: +91 8242428183

Email: rajaniprajith@yahoo.co.in

Received: 22-09-2007

Accepted: 01-04-2008 